http://jmscr.igmpublication.org/home/ ISSN (e)-2347-176x ISSN (p) 2455-0450

crossref DOI: https://dx.doi.org/10.18535/jmscr/v8i4.25

\title{
Small Incision Cataract Surgery under Topical Anaesthesia- A Prospective study to assess its usefulness in cataract patients
}

\author{
Author \\ Dr K.M Suresh, MBBS, MS (OPH) \\ Medical Director Vidya Eye Hospital, Vijayanagar, Bangalore 560040, India
}

\begin{abstract}
With the ever increasing awareness among the urban population, regarding various methods that are available for cataract surgery, it made us inevitable to come out with an acceptable method of anaesthesia in the urban population.

Aim of this study is to find out whether the topical anaesthesia is a safe and a reliable method for performing the small incision cataract surgery (SICS).

Materials and Methods Consisted of 100 cataract patients, who visited the out-patient department of Vidya Eye Hospital, Vijayanagar, Bangalore, Karnataka State, India. Small incision cataract surgery was performed under topical anaesthesia for all these patients. The acceptance of Topical anaesthesia both by the patient and the surgeon were assessed by using relevant criteria in each case.

Results revealed that 93 percent of the patients accepted this method of anaesthesia, while in 94 cases surgeon felt very comfortable by this method of topical anaesthesia.

Conclusion our study concluded that the method of Topical anaesthesia in performing SICS is acceptable both for the patient and the operating surgeon.
\end{abstract}

\section{Introduction}

Local anaesthesia in the form of peribulbar anaesthesia is the standard form of anaesthesia advocated in various textbooks, and by various experienced ophthalmologists. Public awareness in injection-less cataract surgery, used in phacoemulsification and the patients' intentions to undergo the same kind of an operation, in the nonphacoemulsification operations made us, venture into this new technique of doing Small Incision cataract surgery under Topical anaesthesia.

\section{Aim}

Aim of the study was to find out the comfort levels of both the patient and the operating surgeon when this new technique of SICS with Topical anaesthesia was performed and to evaluate the acceptance of this technique from the angle of both the surgeon and the patient. Further analysis was done to find out whether it is acceptable by the patients in general and urban population in particular.

\section{Materials and Methods}

100 patients with cataract in the urban population were selected for the study. Cases which came to the Out-pa tient department of Vidya Eye Hospital, Vijayanagar Bangalore formed the individuals on which this new method of Small Incision Cataract surgery under Topical 
anaesthesia were done and studied. The operations were done under Topcon Ophthalmic operating microscope with X-Y coupling. Standard preoperative assessments were made to assess the prognosis. The cases selected were of simple cataracts. The cases with cataract and associated with other complications were excluded from the study. Attention is paid to note down whether patient is alcoholic or nonalcoholic

Four percent or two percent xylocaine, preservative free was used as an anaesthetic agent in all the surgeries performed. Standard steps followed for SICS in our surgery was painting the eye with povidone iodine, instilling 3 drops of $4 \%$ xylocaine preservative free, using universal speculum for separating the eyelids and exposing the eye ball, oral instruction to the patient to concentrate on the 6 'o' clock meridian of the microscope light, side port at 9 'o'clock position for both injecting tryphan blue and doing CCC (continuous curvilinear capsulorrhexis) under viscoelastic substance, conjunctival flap initiated at 12 'o' clock meridian and extended towards 9 'o' clock and 3 'o' clock meridians of the limbus, cauterization of the vessels, scleroconeal tunnel with crescent knife and keratome, hydrodissection and hydro-delamination, extension of the scleroconeal tunnel depending upon the size of the nucleus, expression of the nucleus by sandwich technique or by irrigating vectis. Xylocaine 2\% preservative free was instilled once in 10 minutes and also when patient complained of mild discomfort.

Cortical wash was given and the residual cortex was agitated, and aspirated by using by-way cannula. Later either foldable IOL or rigid IOL was implanted in the capsular bag.

Pain during operation was evaluated using a VAS (Visual analog Scale) which was presented as a numbered line ranging from 0 (no pain) to 10 (unbearable pain)
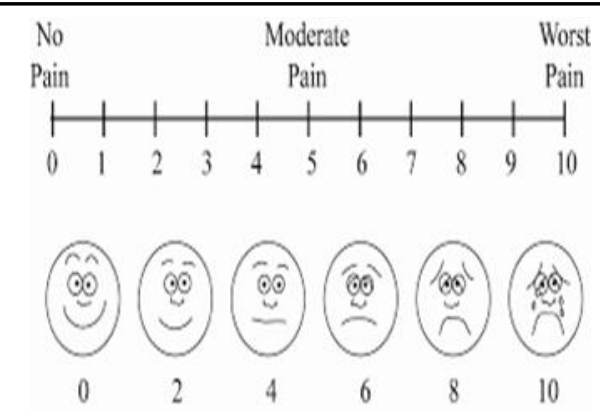

Comfort Level of the surgeon in performing the surgery were graded as

1. Very comfortable

2. Comfortable

3. Slightly difficult,

4. Very difficult

Every patient was informed that this is an injection-less cataract operation. Every patient was asked to score the amount of pain or discomfort experienced by him/her as per the pictorial scoring provided in the VAS pain scoring system. This scoring system was recorded and represented in the form of a graph as shown in the Fig.2

\section{Results}

In our Prospective study of assessing whether Topical Anaesthesia is useful and helpful in performing SICS, we observed that the method was slightly cumbersome for the surgeon initially, later in majority of the cases the surgeon felt no drudgery in the surgery and felt very comfortable in performing the surgery, with lot of ease and comfort. Patients readily accepted the method as no injections were necessary. A few of the patients were not co-operative not because of pain, but because of anxiety. To elaborate the details of the statistics, considering the patients it was found that 93 patients categorically agreed that there was no pain, while 5 patients complained of moderate degree of per-operative pain, which subsided with frequent instillation of topical anaesthesia. 2 patients complained of severe pain- Fig. 2

Viewing from the point of surgeon, it was noted that in 85 cases out of 100 cases, the surgical 
procedure was very comfortable. Surgeon felt the procedure to be comfortable in 8 cases, slightly difficult in one case and very difficult in six cases, as seen in Fig.1

\section{Discussion}

The procedure of doing cataract operation, by Small Incision under topical anaesthesia was rather apprehensive and cumbersome for the surgeon in the initial two to three cases. The main hindrance in initiating the procedure and concluding the procedure was the mobility of the eye. As the ophthalmic surgeon is very much used to operating on the stationary eye, it was difficult to initiate this operation with the eye in an unstable gaze. Even-though the procedure involves, strictly instructing the patient to look at the microscope light, through-out the operation, there is always a tendency for the patient to move the eye in various directions, there by hindering the smooth performance of various steps of the operation. Any way after performing about five surgeries, it becomes very easy for the surgeon to perform the surgery, by various means of stabilizing the position of the eye. In our surgeries we mainly used non- traumatising fine forceps, to stabilize the eye and the eyeball was held by the conjunctiva, close to the limbus, either at $3 \mathrm{o}^{\prime}$ clock or at 6 o' clock meridian.

Main difficulty in these surgeries, in the initial few cases was that the nucleus expression used to become cumbersome, as these patients tend to look superiorly during this step of the operation. These difficulties were overcome by asking the patient strictly to look down during nucleus expression. Incidentally, usage of irrigating vectis helped us to overcome this difficulty. In hysterical or nervous patients, this undue movement was responsible for inadvertent Posterior capsular rent in two cases. Anyway further success rate in these 100 surgeries was due to the confidence and experience we had in operating cataract by phacoemulsification with IOL implantation under topical anaesthesia

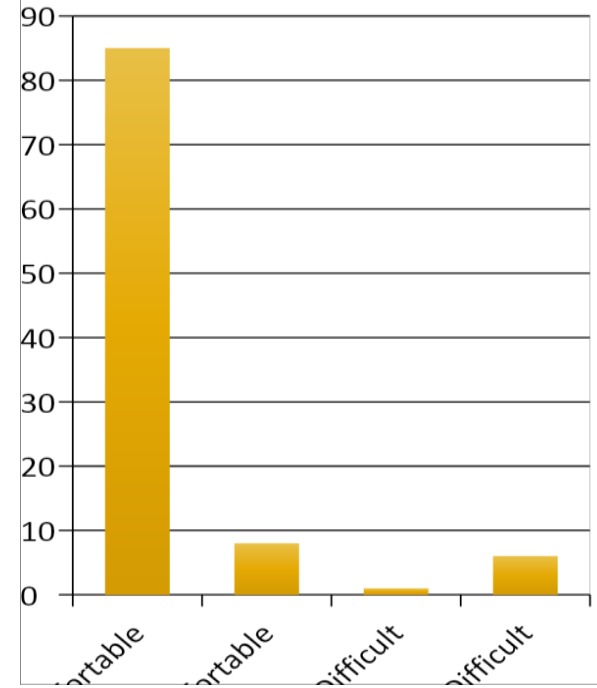

Figure 1 Surgeon's comfort level

\begin{tabular}{|l|c|}
\hline $\begin{array}{l}\text { Pain Thresh-hold } \\
\text { of Patient }\end{array}$ & Number of patients \\
\hline No Pain & 93 patients \\
\hline Moderate Pain & 5 Patients \\
\hline Severe pain & 2 patients \\
\hline
\end{tabular}

\begin{tabular}{|l|c|}
\hline $\begin{array}{l}\text { Comfort Level of } \\
\text { Surgeon }\end{array}$ & $\begin{array}{c}\text { Number of } \\
\text { cases }\end{array}$ \\
\hline Very comfortable & 85 cases \\
\hline Comfortable & 8 cases \\
\hline Slightly Difficult & 1 case \\
\hline Very Difficult & 6 cases \\
\hline
\end{tabular}

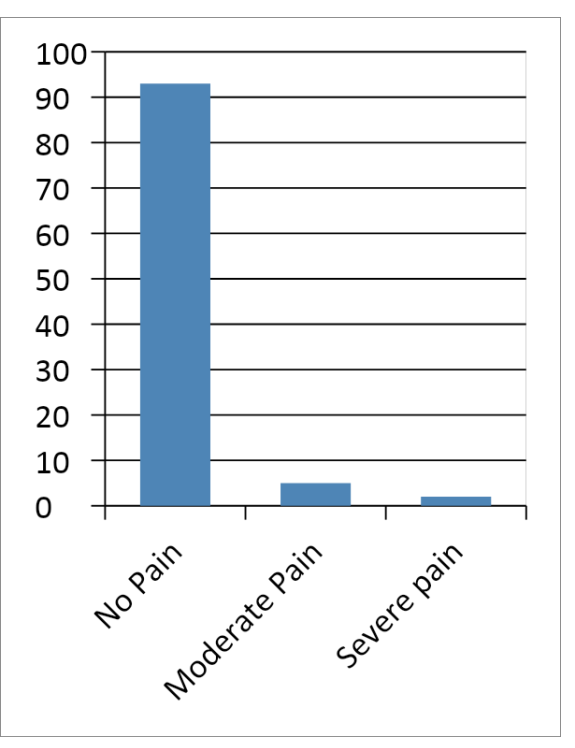

\section{Conclusion}

Our study concluded that practicing the method of Small Incision Cataract Surgery, under the instillation of topical anaesthesia is a safe and acceptable procedure. Even-though, it is slightly difficult to start the procedure, we in our study 
found it to be an easy procedure to follow. It is a well acceptable procedure among the patients, mainly, because, it is an injection-less, painless and suture-less procedure. Hence Small Incision Cataract surgery, under Topical anaesthesia, is an useful method that can be followed and recommended in Cataract surgeries.

\section{References}

1. Projections of the first epidemiological study of incidence of cataract blindness in India. $\mathrm{Br} \mathrm{J}$ Ophthalmol 1990;74:341-3. Hennig A, Kumar J, Singh AK, Ansari A, Singh S, Gurung R, Foster A. World Sight Day and cataract blindness. $\mathrm{Br} \mathrm{J}$ Ophthalmol 2002;86:830-1.

2. Collins SL, Moore RA, McQuay HJ. The visual analogue pain intensity scale: What is moderate pain in millimetres? Pain 1997;72:95-7.

3. Lee J, Stiell I, Hobden E, Wells G. Clinically meaningful values of the visual analog scale of pain severity. Acad Emerg Med 2000;7:550.

4. Smith R. Cataract extraction without retrobulbar anesthetic injection. $\mathrm{Br} \mathrm{J}$ Ophthalmol 1990;74:205-7.

5. Eke, Tom, Thompson, John R. Serious complications of local anaesthesia for cataract surgery: A 1 year national survey in the United Kingdom. Br J Ophthalmol 2007;91:470-5.

6. Nielsen PJ. Immediate visual capability after cataract surgery: Topical versus retrobulbar anesthesia. J Cataract Refract Surg 1995;21:302-4.

7. Eke, Tom, Thompson, John R. Serious complications of local anaesthesia for cataract surgery: A 1 year national survey in the United Kingdom. Br J Ophthalmol 2007;91:470-5.

8. Nielsen PJ. Immediate visual capability after cataract surgery: Topical versus retrobulbar anesthesia. J Cataract Refract Surg 1995;21:302-4.
9. Nielsen PJ. A prospective evaluation of anxiety and pain with topical anesthesia or retrobulbar anesthesia for small incision cataract surgery. Eur J Implant Ref Surg 1995;7:6-10.

10. Maclean H, Burton T, Murray A. Patient comfort during cataract surgery with modified topical and peribulbar anesthesia. J Cataract Refract Surg 1997;23:277-83.

11. Zehetmayer M, Radax U, Skorpik C, Menapace R, Schemper M, Weghaupt H, et al . Topical versus peribulbar anesthesia in clear corneal cataract surgery. J Cataract Refract Surg 1996;22:480-4.

12. Johnston RL, Whitefield LA, Giralt J, Harrun S, Akerele T, Bryan SJ, et al . Topical versus peribulbar anesthesia, without sedation, for clear corneal phacoemulsification. J Cataract Refract Surg 1998;24:407-10.

13. Fichman RA. Use of topical anesthesia alone in cataract surgery. J Cataract Refract Surg 1996;22:612-4.

14. Gozum N, Altan-Yaycioglu R, Gucukoglu A, Arslan O. Does topical anesthesia increase patient's serum cortisol level? Int J Ophthalmol Visual Sci 2003;2:2.

15. Barequet IS, Soriano ES, Green WR, O'Brien TP. Provision of anaesthesia with single application of lidocaine $2 \%$ gel. J Cataract Refract Surg 1999;25:626-31.

16. Assia EI, Pras E, Yehezkel M, Rotenstreich Y, Jager-Roshu S. Topical anesthesia using lidocaine gel for cataract surgery. J Cataract Refract Surg 1999; 25:635-9.

17. Bardocci A, Lofoco G, Perdicaro S, Ciucci F, Manna L. Lidocaine 2\% gel versus lidocaine $4 \%$ unpreserved drops for topical anesthesia in cataract surgery: A randomized controlled trial. Ophthalmology 2003;110:144-9.

18. Soliman MM, Macky TA, Samir MK. Comparative clinical trial of topical anesthetic agents in cataract surgery: 
Lidocaine $2 \%$ gel, bupivacaine $0.5 \%$ drops, and benoxinate $0.4 \%$ drops. J Cataract Refract Surg 2004;30:1716-20.

19. Jacobi PC, Dietlein TS, Jacobi FK. A comparative study of topical vs. Retrobulbar anaesthesia in complicated cataract surgery. Arch Ophthalmol 2000;118:1037-43.

20. Oksuz H, Tamer C. Efficacy of lidocaine $2 \%$ gel in pterygium surgery. Acta Ophthalmol Scand 2005:83:206-9.

21. Kongsap P, Wiriyaluppa C. A comparison of patient pain during cataract surgery with topical anesthesia in prechop manual phacofragmentation versus phacoemulsification. J Med Assoc Thai 2006;89:959-66.

22. Minasian DC, Mehera V. 3.8 Million blinded by cataract each year: Hennig A, Kumar J, Singh AK, Ansari A, Singh S, Gurung R, Foster A. World Sight Day and cataract blindness. $\mathrm{Br} \mathrm{J}$ Ophthalmol 2002;86:830-1.

23. Collins SL, Moore RA, McQuay HJ. The visual analogue pain intensity scale: What is moderate pain in millimetres? Pain 1997;72:95-7.

24. Lee J, Stiell I, Hobden E, Wells G. Clinically meaningful values of the visual analog scale of pain severity. Acad Emerg Med 2000;7:550.

25. Smith R. Cataract extraction without retrobulbar anesthetic injection. $\mathrm{Br} \mathrm{J}$ Ophthalmol 1990;74:205-7.

26. Eke, Tom, Thompson, John R. Serious complications of local anaesthesia for cataract surgery: A 1 year national survey in the United Kingdom. Br J Ophthalmol 2007;91:470-5.
27. Nielsen PJ. Immediate visual capability after cataract surgery: Topical versus retrobulbar anesthesia. J Cataract Refract Surg 1995;21:302-4.

28. Nielsen PJ. A prospective evaluation of anxiety and pain with topical anesthesia or retrobulbar anesthesia for small incision cataract surgery. Eur J Implant Ref Surg 1995;7:6-10.

29. Maclean H, Burton T, Murray A. Patient comfort during cataract surgery with modified topical and peribulbar anesthesia. J Cataract Refract Surg 1997;23:277-83.

30. Zehetmayer M, Radax U, Skorpik C, Menapace R, Schemper M, Weghaupt H, et al . Topical versus peribulbar anesthesia in clear corneal cataract surgery. J Cataract Refract Surg 1996;22:480-4.

31. Johnston RL, Whitefield LA, Giralt J, Harrun S, Akerele T, Bryan SJ, et al . Topical versus peribulbar anesthesia, without sedation, for clear corneal phacoemulsification. J Cataract Refract Surg 1998;24:407-10. 